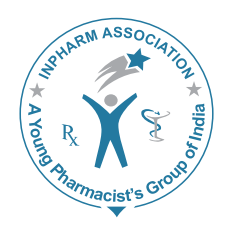

\title{
JVP
}

\section{Pharmaceutical Care: Need of the Hour in India}

\author{
Tumkur A, Muragundi PM, Shetty R${ }^{1}$, Naik A \\ Department of Pharmacy Management, Manipal College of Pharmaceutical Sciences, Manipal University, \\ Manipal, ${ }^{1}$ Department of Cardiology, Kasturba Medical College, Manipal University, Manipal, Karnataka, \\ India
}

Address for correspondence: Prof. A. N. Naik; E-mail: anantha1232000@ gmail.com

\begin{abstract}
Pharmaceutical care signifies a shift of practice in pharmacy from being drug product-oriented to the one that is patient-oriented to achieve definite outcomes that improves patients' quality of life. In order to achieve pharmaceutical care, pharmacists have to assume the role of caregiver, communicator, decision-maker, teacher, researcher, life-long learner, leader, and manager, which will help him to provide individualized care. As the patients visit community pharmacists more often, they can play a major role in providing individual care to the patients especially in the management of chronic noncommunicable diseases (NCDs). Community pharmacists have to upgrade their expertise in drug product orientation to that of clinical orientation to provide patient oriented care. Hence pharmacists have a larger role to play in managing NCDs which are rapidly increasing in India.
\end{abstract}

Key words: Burden of disease, noncommunicable diseases, pharmaceutical care

\section{BURDEN OF DISEASE IN INDIA}

India, accounts for a substantial proportion of the global burden of the disease with $18 \%$ of death and $20 \%$ of the disability adjusted life years (DALYs). Of the estimated 10.3 million deaths that occurred in India in 2004, 5.2 millions were due to chronic conditions. Overall, age standardized mortality rates for chronic conditions were 769 and 602 per 100,000 men and women, respectively. ${ }^{[1]}$ Communicable diseases account for $38 \%$ of the disease burden with large variations across states. Noncommunicable diseases

\begin{tabular}{|l|l|}
\hline \multicolumn{2}{|c|}{ Access this article online } \\
\hline Quick Response Code: & \\
\hline & Website: \\
\hline
\end{tabular}

(NCDs) have evolved as major public health problems and accounted for $53 \%$ of all deaths in the age group 30-59 years in 2005. It is projected that by 2015 these numbers may increase to $59 \%$ of the total deaths in India. ${ }^{[2]}$ Indians were more prone to cardiovascular diseases (CVDs) especially coronary heart diseases (CHDs) at the early age than those people in high income countries. ${ }^{[3]}$ As India's population ages during next 25 years, deaths caused by CVD, projected to reach 4 million in 2030 compared to 2.7 million in 2004. ${ }^{[4]}$ Tobacco is widely consumed and remains as the most important preventable risk factor with $47 \%$ of men and $15 \%$ of women being regular consumers of tobacco. Road traffic injuries result in the death of more than 100,000 people every year. Even though NCDs are usually expected to occur in the old age, their peak occurrence in India is a decade earlier than western countries. Hence, the issue is not only the burden, but also its prematurity and the resulting socioeconomic consequences. $^{[5]}$ 
India's total expenditure on health was estimated to be $4.2 \%$ of GDP in 2009 of which public expenditure on health was estimated to be $1.10 \% .{ }^{[6]}$ Out of pocket expenditure as a percentage of private expenditure on health in India is 74.4 (WHO-2010) which has great impact on livelihood of patients. In 2004-2005, about $14 \%$ of rural and $12 \%$ urban households spent more than $10 \%$ of their total expenditure on healthcare, leading to poverty. Thirty-nine million people (30.6 million in rural areas and 8.4 million in urban areas) fell into poverty as a result of out of pocket expenditure for health care needs in 2004-2005 and are increasing day-by-day. ${ }^{[7]}$

Only about $10 \%$ of the Indian populations are covered by any form of social or voluntary health insurance, which is mainly offered through government schemes for selected employment groups in organized sector (e.g, State Employees Insurance) and private insurance companies account for $6.1 \%$ of health expenditures on insurance. Expenditure on drugs has been increasing with time, and drug costs constitute a greater proportion of out of pocket expenditures for people who are poor than for those who are not. Inefficient control of drug prices, regulation of pharmaceutical market, and procurement and distribution mechanisms exacerbate inequitable access to affordable good quality drugs. Analysis of changes in drug prices has shown that the cost of the selected group of drugs rose by $40 \%$, whereas essential drugs rose by $15 \%$ and for those which are not on the controlled list and not price controlled rose by $33 \%{ }^{[8]}$ Inadequate protection of financial risks against financial shocks that are associated with the cost of medical treatment (inpatient care, drugs, diagnostic test, and medical appliances) has worsened the poverty in many households..$^{[9,10]}$

\section{PHARMACEUTICAL CARE}

Globally, there have been significant changes in health care systems with respect to their quality and processes, and these have been specifically demonstrated in the practice of pharmacy. The traditional role of the pharmacist involving in the preparation, dispensing and selling of medications is no longer adequate. It signifies shift of practice in pharmacy from drug product-oriented to patient-oriented. The new approach has been given the name as pharmaceutical care. The most generally accepted definition of this new approach is: "Pharmaceutical care is the responsible provision of drug therapy for the purpose of achieving definite outcomes that improve a patient's quality of life". ${ }^{[1]]}$ In adopting this definition in 1998, the International Pharmaceutical Federation (FIP) added one significant amendment: "achieving definite outcomes that improve or maintain a patient's quality of life".

The goal of pharmaceutical care is to optimize the patient's health-related quality of life, and achieve positive clinical outcomes, within realistic economic expenditures. In order to fulfill this obligation, the pharmacist has to assume many different functions. The concept of the sevenstar pharmacist, introduced by WHO and taken up by FIP in 2000 in its policy statement on Good Pharmacy Education Practice, visualizes the pharmacist as a caregiver, communicator, decision-maker, teacher, researcher, life-long learner, leader, and manager. ${ }^{[12]}$

Patients need pharmacist's services at the time they are receiving health care. Successful pharmacotherapy is specific for each patient. It includes individual drug therapy decisions, reaching an agreement between the patient and the health care provider on the therapeutic outcome - cure of a disease, elimination or reduction of a patient's symptoms, arresting or slowing a disease process or symptoms, and critical patient monitoring activities. For each individual patient's drug treatment, the pharmacist develops a care plan together with the patient. A systematic approach to patient care is illustrated in Figure 1.

Pharmacists are well suited to identify and resolve Medication related problems and provide medication education to patients and their families to prepare them to manage medication therapy following discharge from hospitals. Such activities are fundamental to pharmaceutical care and are embodied in the 2015 goals of the American Society of HealthSystem Pharmacists. ${ }^{[14]}$ Redesigned discharge processes that incorporate pharmacists to address transitional care needs have been piloted by various institutions and suggest that pharmacist-specific interventions such as medication

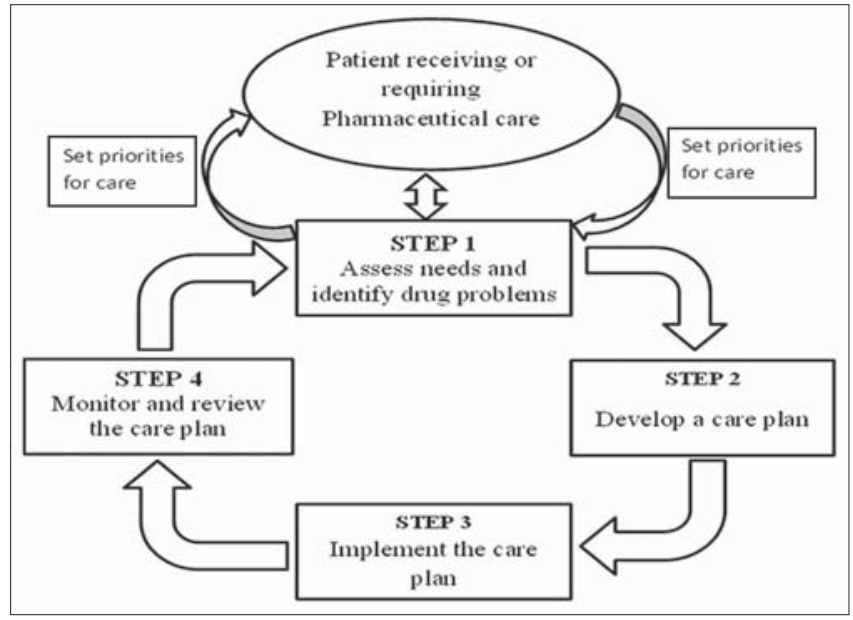

Figure 1: Systematic approach for pharmaceutical care ${ }^{[13]}$ 
reconciliation, patient counselling, follow-up telephone calls, and the specific role of pharmacist transition coordinators can result in identification and resolution of medication discrepancies, reduce the incidence of preventable ADEs after discharge, and decrease the number of return visits to the emergency department, and to ensure the quality use of medicines and positive health outcomes. ${ }^{[1]}$

The pharmaceutical care model ${ }^{[16]}$ has clearly indicated the gap in healthcare and possibility of causalities due to the absence of team work of healthcare service providers. Pharmacists, being the expert in a matter of medicines, are in a unique position to think from a different angle than the physicians and nurses due to professional orientation and training. The healthcare services in developed countries are satisfactorily safe due to collaborative healthcare services by physicians, nurses, and pharmacists. The holistic approach and access of pharmacists, quality use of medicines, and evidence based medicine cannot happen in the absence of contributions of paramedical staff.

When a patient is experiencing or has the potential to experience an undesirable effect, which may be psychological, physiological, economic or social origin leading to drugrelated problems (DRP), the pharmacist has to identify and prevent or resolve each of these. ${ }^{[17]}$ These are listed below:

1. Needing pharmacotherapy, but not receiving it.

2. Taking or receiving the wrong drug.

3. Taking or receiving too little of the correct drug.

4. Taking or receiving too much of correct drug.

5. Experiencing an adverse drug reaction.

6. Experiencing an drug-drug, drug-food reaction.

7. Not taking or receiving the drug prescribed.

8. Taking or receiving a drug for which there is valid medical indication.

\section{SYSTEMATIC APPROACH TO PHARMACEUTICAL CARE}

Pharmaceutical care is prospective, patient specific and requires pharmacist's dedication towards it. Table 1 summarizes the nine steps which have to be completed by a pharmacist for providing pharmaceutical care to a patient. The services offered by the pharmacist before or at the time of drug therapy decision are more helpful to avoid further DRPs. The necessary information about patient's clinical characteristics (age, sex, socio economic status, and biochemistry lab values) pharmacotherapy (allergy, recent, or past pharmacotherapy) and disease process (severity, prognoses) will be significant. In the process of pharmaceutical care, pharmacists should strive for the best interest of the patient while respecting the sovereignty and confidentiality of patient, which is essential for the delivery of pharmaceutical care. Documentation of care process should include information needed to make and take decisions, records the decisions about individualized pharmacotherapy and pharmacist's actions on outcomes of the therapy. Database of the pharmaceutical care process consists of patient details, drug, disease, drug choice, dose determinations, route of administration, procedures and standards of patient monitoring and patient outcomes in terms of efficacy, length of illness, side effects etc., which is an inherent property of care process. ${ }^{[17]}$

Over the last few years, many studies have shown improvements in patient outcomes, when pharmaceutical care provided by community pharmacists in the conditions such as hypertension, diabetes, dyslipidemia, asthma, coronary artery diseases, etc., and also geriatric patients. Table 2 depicts the some important publications showing the effect of pharmaceutical care. ${ }^{[18-20]}$

Nowadays, pharmaceutical care has become a dominant form of practice for thousands of pharmacists all over the world. However, for the patients and pharmacists in India, this concept remains unknown because it was not being performed as a routine, and pharmacists especially community pharmacists were not aware of the same. It is important to emphasize the fact that pharmaceutical care is aimed to achieve rational and evidence-based pharmacotherapy, which is beneficial for patient and society. ${ }^{[21]}$ Independent pharmacies in developing nations can play an important role in reducing mortality, providing continuity of care, and improving life expectancy. ${ }^{[22]}$

India needs sustainable, high quality human resources for health with a variety of skills and who are adequately distributed in all states, particularly in rural areas. ${ }^{[23]}$ The public health system has

Table 1: An overview of the pharmaceutical care process $^{[17]}$

The pharmaceutical care process: An overview

Step 1 Establish relationship with the patient: Contact and commitment to the patient

Step 2 Collect, synthesize, and interpret the relevant information: Patient, drug, and disease data - interpret as pharmacists

Step 3 List and rank the patient's DRPs: Define and prioritize

Step 4 Establish a desired pharmacotherapeutic outcome for each DRP: Quantitative and measurable

Step 5 Determine feasible pharmacotherapeutic alternatives: Desired outcomes

Step 6 Choose the best pharmacotherapeutic solutions and individualize the regimen

Step 7 Design a therapeutic drug monitoring plan: Monitor therapeutic outcome and adverse effect

Step 8 Implement the individualized regimen and monitoring plan: Documentation

Step 9 Follow-up to measure success: Patient's basis and long-term basis 
Table 2: List of some important publications showing the effect of pharmaceutical care

\begin{tabular}{|c|c|c|c|}
\hline Reference, service & Study design and sample size & Major selected outcome reported & Results \\
\hline Stowasser et af. ${ }^{[18]}$ & Randomized $(n=243)$ & Patients with $>1$ pharmacist intervention & $P<0.05$ \\
\hline \multirow[t]{2}{*}{ Admission and discharge } & $I=113$ & Patients with $>1$ medication change & $P<0.05$ \\
\hline & $C=127$ & & \\
\hline Bolas et a $\left[.^{[19]}\right.$ & Randomized $(n=162)$ & Errors in drug therapy knowledge & \\
\hline \multirow[t]{3}{*}{ Discharge } & $I=81$ & Drug name & $P<0.001$ \\
\hline & $C=81$ & Drug dose & $P<0.001$ \\
\hline & & Dosage frequency & $P<0.001$ \\
\hline Lipton and Bird & Randomized $(n=706)$ & Medication compliance & $P<0.001$ \\
\hline \multirow[t]{2}{*}{ Discharge and follow-up } & $I=350$ & Medication knowledge & $P<0.001$ \\
\hline & $C=356$ & Poly pharmacy assessment @ 12 weeks & $P<0.001$ \\
\hline Al Rasheed et al. ${ }^{[20]}$ & Randomized $(n=83)$ & Medication compliance & $P<0.001$ \\
\hline \multirow{2}{*}{$\begin{array}{l}\text { Discharge and outpatient } \\
\text { coordination }\end{array}$} & $I=43$ & GP visit & $P<0.05$ \\
\hline & $C=40$ & Readmission@3weeks & $P<0.05$ \\
\hline Montgomery et al. & Cross-sectional study ( $n=534)$ & Medication knowledge & $P<0.01$ \\
\hline \multirow[t]{2}{*}{ Community pharmacy } & $I=258$ & General health & $P<0.001$ \\
\hline & $C=276$ & Systolic BP & $P<0.001$ \\
\hline Aguwa et al. & Cross over $(n=24)$ & Diastolic BP & $P<0.001$ \\
\hline Community pharmacy & & Physical QoL & $P<0.001$ \\
\hline $\begin{array}{l}\text { Lyra et al. } \\
\text { Outpatients }\end{array}$ & Nonrandomized $(n=30)$ & HQoL & $P<0.05$ \\
\hline
\end{tabular}

a shortage of medical and para medical personnel. Government estimates indicate that $16 \%$ are without a pharmacist. Hence, there is a need to develop a national human resource policy, which examines the creation and establishment of cadres of trained healthcare professionals who can provide leadership and direction to the health sector to meet global standards. It should also make use of available pharmacists and train them in the pharmaceutical care area leading to sustainable human resource for the health care.

\section{INDIAN PERSPECTIVE}

In India, pharmacists had a little role in the healthcare services. The management of patient's therapy is managed by physicians with the help of nursing faculty thus leading to underutilization of services and knowledge of pharmacists. Physicians, who are unfamiliar with services of pharmacists, may be declined to give authority to less qualify as perceived. Provision of pharmaceutical care, complete documentation of pharmacotherapy process, and achieving cost effective use of resources ultimately lead to formation of a comprehensive health care system. A positive mutual relationship with all healthcare professionals is beneficial for patient's outcomes.

The patients visit retail pharmacies often to buy the prescribed medicines. Retail pharmacy is best suited to provide the individualized patient care by providing patient counseling, reviewing of prescriptions, detection of potential side effects, etc. Pharmacists are in a position to communicate any therapy-related information to the physician so that he can adopt appropriate correction to the therapy.

Worldwide, pharmacy education is more clinical in orientation, while in India it is having an industrial orientation. There is a need for the change in the curriculum of the pharmaceutical education in India, making amendments to include the concept of pharmaceutical care into Diploma, Under graduate as well as Master's degree. In this regard, introduction of Pharm D course and M. Pharm in Pharmacy practice has changed the mindset of students of pharmacy towards the need of people and other health care professionals. Community pharmacists, who comprises around 55\% of total pharmacists in India, getting sufficient exposure, training through continuing pharmaceutical education and workshops in the pharmaceutical care will surely help to achieve the goal of "Health for All by 2020". Pharmacists are a part of the health care services to patients and this may change the social status of pharmacists.

In India, the pharmacy act and education regulation for Pharm D was enacted and the first batch of Pharm D (Post Baccalaureate) are available for service. There are 85 colleges offering the course in India, most of which are located in Southern India. The demand for the Pharm D course is good, and many institutions are surviving by Pharm D course as conventional B. Pharm have lost the demand due to a large number of educational institutions to the tune of thousands. The practice of clinical pharmacy in hospital has already begun, and 
doctors are realizing the importance of pharmacists in healthcare system. The services such as drug information, adverse drug reaction monitoring, and ward round participation are gaining popularity and physicians are feeling convenient by sharing the responsibilities with the pharmacists. The current syllabus of Pharm D and Post Baccalaureate has enough opportunities for the interns to work and learn appropriate clinical skills to practice the pharmacy profession in hospitals and in community. Apart from basic sciences, interns do clerkship and 12 months internship, visiting almost all clinical departments. There were a lot of skeptics for the course and many experts expressed their doubts of accepting pharmacists in the clinical setup. However, the change is getting accepted and gaining popularity due to the significance of pharmaceutical care in hospitals.

The current job opportunities for clinical pharmacists are yet to open, and there is a need for professional bodies to advocate policy makers to create a structural career prospectus for Pharm. D like in other developed countries.

Common man in India has become aware regarding the quality of health care services and has begun to demand for quality services. The current system is burdened, and unable to sustain the service expectations. Issues like inappropriate use of medicines and exploitation of ignorance of patients have been questioned in consumer forums. The apex professional bodies like Medical Council of India are expected to act in the interest of patients rather than its own members. The doctors are needed to explain the treatment in detail to patients/patient party. The number of patient seen by physician is increasing to all time high leaving the little time to educate patients in the aspects of lifestyle modifications, use of medicines, and diseases. There are numerous opportunities for the pharmacist to assist the physicians in the hospitals and as well as retail pharmacies.

Pharmaceutical care is a systematic process designed to identify and resolve DRPs, and individualize the pharmacotherapy, documentation and achieve economical, clinical, and humanistic outcomes while respecting sovereignty, confidentiality of the patient by committed pharmacists.

\section{REFERENCES}

1. WHO. Disease and injury country estimates. Death and DALY estimates for 2004 by cause for WHO member states. Department of Measurement and Health Information. 2009. Available from: http://www.who.in/healthinfo/ global_burden_estimates_country/en/index.html. [Last accessed on 2010 Oct 13].
2. Preventing chronic diseases: A vital investment. Geneva: WHO; 2005. Available from: http://www.who.int/chp/chronic_disease_report/ full_report.pdf. [Last accessed on 2011 Dec 3].

3. Leeder S, Raymond S, Greenberg H, Liu H, Esson K. A race against time: the challenge of cardiovascular disease in developing countries. New York: Trustees of Columbia University; 2004.

4. Patel V, Chatterji S, Chisholm D, Ebrahim S, Gopalakrishna G, Mathers C, et al. Chronic diseases an injuries in India. Lancet 2011;377:413-28.

5. The Country Cooperation Strategy briefs. World Health Organization 2006. Available from: http://www.who.int/countryfocus/cooperation_strategy/ ccsbrief_ind_en.pdf. [Last accessed on 2011 Dec 3].

6. Government of India. National Health Accounts-India (2004-05) - with provisional estimates from 2005-06 to 2008-09). National Health Accounts Cell. New Delhi: Ministry of Health and Family Welfare; 2009.

7. Selvaraj S, Karan A. Deepening health insecurity in India: Evidence from national sample surveys since 1980s. Econ Polit Wkly 2009;44:55-60.

8. Selvaraj S, Nabar V. Acecess to medicines in India: issues, challenges and response. In: Mahal A, Debroy B, Bhandari L, editors. India Health Report-2010. New Delhi: Business standard Limited; 2010. p. 83-96.

9. Yip W, Mahal A. The health care systems of China and India. Performance and future challenges. Health Aff (Millwood) 2008;27:921-32.

10. Mahal A, Karan A, Engelgau M. The economic implications of non communicable disease for India. Health, nutrition and population discussion paper. Washington, DC: World Bank; 2010.

11. Hepler CD, Strand LM. Opportunities and responsibilities in pharmaceutical care. Am J Hosp Pharm 1990;47:533-43.

12. The role of the pharmacist in the health care system. Preparing the future pharmacist: Curricular development. Report of the third WHO Consultative Group on the Role of the Pharmacist, Vancouver, Canada, 27-29 August 1997. Geneva: World Health Organization; 1997. Document no. WHO/ PHARM/97/599. Available from: http://www.who.int/medicines/. [Last accessed on 2010 Oct 3].

13. Counselling and advice on medicines and appliances in community pharmacy practice. Clinical Resource and Audit Group. Edinburgh: The Scottish Office, NHS in Scotland; 1996.

14. American Society of Health-System Pharmacists. 2015 Health- System Pharmacy Initiative. Available from: http://www.ashp.org/2015. [Last accessed on 2010 Oct 15].

15. Schnipper JL, Kirwin JL, Cotugno MC, Wahlstrom SA, Brown BA, Tarvin $\mathrm{E}$, et al. Role of pharmacist counseling in preventing adverse drug events after hospitalization. Arch Intern Med 2006;166:565.

16. Developing pharmacy practice. A focus on patient care. Available from: http://www.who.int/medicines/publications/WHO_PSM_ PAR_2006.5.pdf. [Last accessed on 2011 Dec 3].

17. Strand LM, Cippolle RJ, Morley PC. Pharmaceutical care: An introduction. Upjohn Co; 1992. p. 14-29.

18. Stowasser DA, Collins DM, Stowasser M. A randomised controlled trial of medication liaison services--patient outcomes. J Pharm Pract Res 2002;32:133-40.

19. Bolas H, Brookes K, Scott M, McElnay J. Evaluation of a hospital-based community liaison pharmacy service in Northern Ireland. Pharm World Sci 2004;26:114-20.

20. Al Rashed SA, Wright DJ, Roebuck N, Sunter W, Chrystyn H. The value of inpatient pharmaceutical counselling to elderly patients prior to discharge. Br J Clin Pharmacol 2002;54:657-64.

21. Berenguer B, La Casa C, de la Matta MJ, Martin-Calero MJ. Pharmaceutical care: Past, present and future. Curr Pharm Des 2004;10:3931-46, 26.

22. Patel I, Chang J, Srivatsa J, Balkrishnan R. Mortality in the developing world - Can pharmacists intervene? Indian J Pharm Pract 2011;4:1-9.

23. Rao M, Rao KD, Shivakumar AK, Chaterjee M, Sundararaman T. Human resources for health in India. Lancet 2011;377:587-98.

How to cite this article: Tumkur A, Muragundi PM, Shetty R, Naik A. Pharmaceutical care: Need of the hour in India. J Young Pharmacists 2012;4:282-6

Source of Support: Nil, Conflict of Interest: None declared. 